\title{
Association of retroperitoneal fibrosis, proctitis and rectal stenosis
}

\author{
R. Manna \\ M.D. \\ M. G. PIGINI
M.D. \\ M. A. Pala \\ M.D.
}

E. Caturelli

M.D.

M. C. LANZA-TomaSI

M.D.

E. ZuPI

M.D.

Istituto di Patologia Speciale Medica, Università Cattolica del Sacro Cuore, Roma

\begin{abstract}
Summary
Retroperitoneal fibrosis (RF) in most cases is 'idiopathic'. In the case reported, RF could be the result of a proctitis that followed a haemorrhoidectomy.

\section{Introduction}

Retroperitoneal fibrosis (RF) is a fibrotic process in the retroperitoneum, that often causes ureteral obstruction. This condition, first described by Albarran in 1905, became an established clinical entity in 1948 owing to the work of Ormond. Studying the origins of this illness, Koep and Zuidema (1977) reviewed 481 cases of RF, of which $68 \%$ were considered idiopathic. This study presents a case of RF following a proctitis which ended in rectal stenosis.
\end{abstract}

\section{Case report}

A 67-year-old man was admitted complaining of burning nocturnal lumbar pain, localized at the 2 last lumbar vertebrae and which spread out anteriorly; intermittent fever $\left(37.5-38^{\circ} \mathrm{C}\right)$; loss of weight ( $7 \mathrm{~kg}$ in 2 months); anorexia and periumbilical pain. An ESR performed just before admission was $100 \mathrm{~mm} / \mathrm{hr}$. Before admission, the patient had occasionally used analgesics (pyrazolone), corticosteroids and anticholinergic drugs, without improvement of his symptoms.

Two years previously he had undergone surgery for haemorrhoidectomy, with subsequent proctitis and rectal stenosis; this last was treated with periodic dilatations. No other important element was found in his physiological and family history.

The clinical examination showed no abnormality.

The laboratory tests showed a mild microcytic anaemia (Hb was $11 \mathrm{~g} / \mathrm{dl}$, MCV $80 \mathrm{fl}$ ), a high ESR $(116 \mathrm{~mm} / \mathrm{hr})$, an elevated blood urea $(5.98 \mathrm{mmol} / \mathrm{l}$, haematuria, an increased concentration of $\alpha_{2}$-glob ulins $(18 \%)$ and a reduction of albumin $(38 \%)$ o $\bar{P}$ the protein electrophoresis, a reduction of creatinin $\overrightarrow{8}$ clearance $(35 \mathrm{ml} / \mathrm{min})$ and a mild iron deficiencys Auto-antibody screen (to the nuclei, DNA and mitochondria) and immunoglobulins levels were normal; cryoglobulins, L.E. cells and Bence-JoRes protein were absent.

Radiology of the lumbar spine showed no sin of metastatic lesions; urography showed dela elimination of the contrast agent by the left kidney $\frac{5}{2}$ and subsequently severe left ureteropyelectasia due to external ureteral obstruction in the middle thirdo of probable retroperitoneal origin. The renas scintigram showed an irregular accumulation of th $\vec{\xi}$ radio-isotope in the left kidney, without evidence o $\mathbb{B}$ defects suggesting neoplastic disease.

A CT-scan of the pelvis confirmed left hydro? nephrosis, caused by a widespread process witho

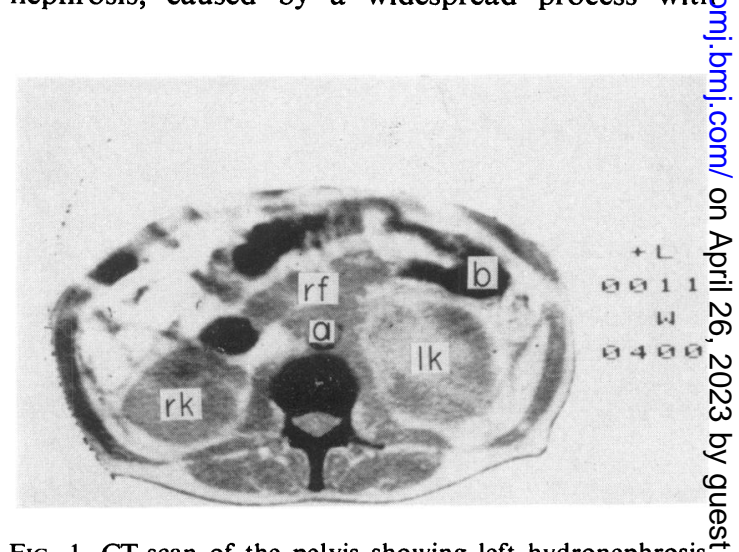

FIG. 1. CT-scan of the pelvis showing left hydronephrosis: $\mathrm{rf}=$ retroperitoneal fibrosis; $\mathrm{a}=$ aorta; $\mathrm{rk}=$ right kidney; $\mathrm{lk}=$ left kidney with hydronephrosis; $\mathrm{b}=$ bowel. 
boundaries involving the left ureter, and also involving the aorta, inferior cava and iliac arteries.

Exploratory laparatomy revealed dense retroperitoneal fibrous tissue, mainly extended on the left abdominal wall, with a pseudo-sarcomatous appearance; multiple biopsies showed RF. Left nephrectomy was performed.

Histology of the removed tissues showed hydronephrosis and subacute pyelitis in the kidney, a fibrous process with chronic follicular and granulomatous inflammation in the retroperitoneum, and a reactive lymphadenitis in the lymph nodes. The ureter was wrapped in dense fibrous connective tissue, sprinkled with inflammatory elements, similar to those described above.

The postoperative period was uneventful. Treatment with corticosteroids started immediately after surgery. ESR, serum creatinine and blood urea decreased rapidly. Fever and pain disappeared. The patient was discharged after a few days in good condition.

\section{Discussion}

It is thought that the RF in this case could be the result of a pathological process not previously described, namely an extension of proctitis to the retroperitoneal space (including lymph nodes), possibly with the migration of micro-organisms. On the other hand, the tendency for developing sclerosing responses, probably as a manifestation of a non-inflammatory or, more probably, inflammatory systemic disease (collagen-vascular-like process) could already be recognized in the rectal stenosis that followed the haemorrhoidectomy (see histological changes in the experimental model of 'animal-induced hypersensitivity'; Goddard, 1947).

From a therapeutic point of view, the result of combined surgery and corticosteroid therapy in this patient must still be evaluated in time. It is interesting to note that Jones et al. (1970) obtained remission of this disease in all their patients by this therapeutic procedure. Ross and Goldsmith (1971) also had good responses. These results must lead physicians to more careful research of $\mathrm{RF}$ in patients with lumbar or abdominal pain, considering the strong possibility of therapeutic success.

\section{Appendix}

Reported causes of retroperitoneal fibrosis

(a) malignant tumours: peri-ureteral metastasis (Grabstald and Kaufman, 1969); primary retroperitoneal tumours, serotonin-producing carcinoid tumours (Morin and Zuerner, 1971);

(b) any type of retroperitoneal lesion stimulating the retroperitoneum: haemorrhages with subsequent haematomas; Henoch's purpura (Cerny and Scott, 1971; Hacke, Utz and Woolner, 1962) ; factor VII deficiency (Popham and Stevenson, 1960); abdominal aneurysms (Charnock, Riddel and Lombardo, 1961); trauma in the suprapubic region (Webb and Dawson-Edwards, 1967);

(c) Crohn's disease, intestinal diverticulitis, retroperitoneal appendicitis (Harlin and Hamm, 1952);

(d) peri-pelvic urinoma subsequent to urinary obstruction (Jones et al., 1970);

(e) radiotherapy (Koep and Zuidema, 1977);

(f) pelvic surgery, with sectioning of the ureter followed by extravasation of urine (Koep and Zuidema, 1977);

(g) primary infections of the genito-urinary tract, with transmission of micro-organisms to the retroperitoneum (Winsbury-White, 1933);

(h) histoplasmosis, often associated with mediastinal and retroperitoneal fibrosis (Wieder and Rabinowitz, 1977);

(i) use of certain drugs, e.g. methysergide (Litz and Rooke, 1965); vaso-active drugs (Stecker et al., 1974; Saxton et al., 1969); methyldopa (Iversen et al., 1975);

(j) association with auto-immune disorders: vasculitis (Hellstrom and Perez-Stable, 1966); Weber-Christian's panniculitis (Mitchinson, 1965); scleroderma (Mansell and Watts, 1980); processes of sclerosing fibrosis as fibrotic orbital granuloma, Riedel's struma, sclerosing cholangitis, mediastinal and retroperitoneal fibrosis (Arger, Stolz and Miller, 1973; Bartholomew et al., 1963; Gleeson, Taylor and Dowling, 1970; Kittredge and Nash, 1974; Mitchinson, 1970; Palmer, Wolfe and Kostas, 1978).

\section{References}

Albarran, J.J. (1905) Rétention rénale par périurétérite; libération externe de l'urétère. Association Française d'Urologie, 9, 511 .

Arger, P.H., Stolz, J.L. \& Miller, W.T. (1973) Retroperitoneal fibrosis: an analysis of the clinical spectrum and roentgenographic signs. American Journal of Roentgenology, Radium Therapy and Nuclear Medicine, 119, 812.

Bartholomew, L.G., CaIn, J.C., Woolner, L.B., Utz, D.C. \& FERRIS, D.O. (1963) Sclerosing cholangitis: its possible association with Riedel's struma and fibrous retroperitonitis: report of two cases. New England Journal of Medicine, 269, 8.

Cerny, J.C. \& Scott, T. (1971) Non-idiopathic retroperitoneal fibrosis. Journal of Urology, 105, 49.

Charnock, D.A., Riddel, H.I. \& Lombardo Jr, L.J. (1961) Retroperitoneal fibrosis producing ureteral obstruction. Journal of Urology, 85, 251.

Gleeson, M.H., Taylor, S. \& Dowling, R.H. (1970) Multifocal fibrosclerosis. Proceedings of the Royal Society of Medicine, 63, 1309.

GoDDARD, J.W. (1947) Granuloma, a characteristic 'qualitative' change in focal anaphylactic inflammation. American Journal of Pathology, 23, 943.

Grabstald, H. \& Kaufman, R. (1969) Hydronephrosis secondary to metastatic breast cancer giving ureteral obstruction. Journal of Urology, 102, 569.

HACKe, L., UTz, D.C. \& Woolner, L.B. (1962) Idiopathic fibrous retroperitonitis. Surgery, Gynecology and Obstetrics, 115, 737. 
HaRlin, H.C. \& Hamm, F.C. (1952) Urologic disease resulting from nonspecific inflammatory conditions of the bowel. Journal of Urology, 68, 383.

Hellstrom, H.R. \& Perez-Stable, E.C. (1966) Retroperitoneal fibrosis with disseminated vasculitis and intrahepatic sclerosing cholangitis. American Journal of Medicine, 40, 184.

Iversen, B.M., Nordahl, E., ThunNold, S., Johannesen, J.W., Opsted, J. \& Willassen, Y. (1975) Retroperitoneal fibrosis during treatment with methyldopa. Lancet, ii, 302.

Jones, J.H., Ross, E.J., MATZ, L.R., EDWARDS, D. \& DAvies, D.R. (1970) Retroperitoneal fibrosis. American Journal of Medicine, 48, 203.

KitTredGe, R.D. \& NASH, A.D. (1974) The many facets of sclerosing fibrosis. American Journal of Roentgenology, Radium Therapy and Nuclear Medicine, 122, 288.

KOEP, L. \& ZuIDEMA, G.D. (1977) The clinical significance of retroperitoneal fibrosis. Surgery, 81, 250.

LITZ, D.C. \& Rooke, E.D. (1965) Retroperitoneal fibrosis in patients taking methysergide. Journal of the American Medical Association, 191, 983.

Mansell, M.A. \& WATts, R.W.E. (1980) Retroperitoneal fibrosis and scleroderma. Postgraduate Medical Journal, 56, 730 .

Mitchinson, M.J. (1965) Systemic idiopathic fibrosis and systemic Weber-Christian disease. Journal of Clinical Pathology, 18, 645.

Mitchinson, M.J. (1970) The pathology of idiopathic retroperitoneal fibrosis. Journal of Clinical Pathology, 23, 681.

MORIN, L.J. \& ZUERnER, R.T. (1971) Retroperitoneal fibrosis and carcinoid tumor. Journal of the Americ Medical Association, 216, 1647.

ORMOND, J.K. (1948) Bilateral ureteral obstruction due ta envelopment and compression by an inflammato retroperitoneal process. Journal of Urology, 59, 1072.

Palmer, P.E., Wolfe, H.J. \& Kostas, C.I. (1978) Mul民 system fibrosis in alpha $a_{1}$-antitrypsin deficiency. Lancet, 221.

PoPhAM, B.K. \& Stevenson, T.D. (1960) Idiopathic retrôे peritoneal fibrosis associated with coagulation defeet (factor VII deficiency). Annals of Internal Medicine, $5 \%$ 894.

Ross, J.C. \& Goldsmith, H.J. (1971) The combined surgic $\vec{\Re}$ and medical treatment of retroperitoneal fibrosis. British Journal of Surgery, 58, 422.

Saxton, H.M., Kilpatrick, F.R., Kinder, C.H., Lessog M.H., MCHARdY-Young, S. \& WardLe, D.F.H. (196) Retroperitoneal fibrosis. A radiological and followstudy of 14 cases. Quarterly Journal of Medicine, 38, 15

SteCkER, J.F., Rawls, H.P., Devine, C.J. \& DeVINe, P.\& (1974) Retroperitoneal fibrosis and ergot derivatés Journal of Urology, 112, 30.

Webi, A.J. \& Dawson-Edwards, P. (1967) Malignagy retroperitoneal fibrosis. British Journal of Surgery, 54, 505

WIEDER, S. \& RABINOWITZ, J.G. (1977) Fibrous mediasti范itis: a late manifestation of mediastinal histoplasmosis. Radiology, 125, 305.

WinSBURY-White, H.P. (1933) The spread of infection from the uterine cervix to the urinary tract and the ascent of infection from the lower urinary tract to the kidney British Journal of Urology, 5, 249. 